\title{
Intracranial pressure monitoring associated with increased mortality in pediatric brain injuries
}

\author{
Patrick T. Delaplain ${ }^{1}$ (D) Areg Grigorian ${ }^{1} \cdot$ Michael Lekawa $^{1} \cdot$ Michael Mallicote $^{2} \cdot$ Victor Joe $^{1} \cdot$ Sebastian D. Schubl $^{1}$. \\ Catherine M. Kuza ${ }^{3} \cdot$ Matthew Dolich ${ }^{1}$. Jeffry Nahmias ${ }^{1}$
}

Accepted: 3 January 2020 / Published online: 14 January 2020

○) Springer-Verlag GmbH Germany, part of Springer Nature 2020

\begin{abstract}
Background Utilization of ICP monitors for pediatric patients is low and varies between centers. We hypothesized that in more severely injured patients (GCS 3-4), there would be a decreased mortality associated with invasive monitoring devices. Methods The pediatric Trauma Quality Improvement Program (TQIP) was queried for patients aged $\leq 16$ years meeting criteria for invasive monitors. Our primary outcome was mortality. Patients with ICP monitoring were compared to those without. A logistic regression was used to examine the risk of mortality.

Results Of 3,808 patients, 685 (18.0\%) underwent ICP monitoring. ICP monitors were associated with increased risk of mortality (OR 1.82, CI 1.36-2.44, $p<0.001$ ). A secondary analysis including type of invasive ICP monitor and dividing GCS into 3 categories revealed both intraventricular drain (OR 1.89, CI 1.3-2.7, $p=0.001$ ) and intraparenchymal pressure monitor (OR 1.86, CI 1.32-2.6, $p<0.001$ ) to be independently associated with an increased likelihood of mortality regardless of GCS, while intraparenchymal oxygen monitoring was not (OR 0.47 , CI $0.11-2.05, p=0.316$ ). The strongest effect was seen in those patients with a GCS of 5-6.

Conclusion ICP monitors are an independent risk factor for mortality, particularly with intraventricular drains and intraparenchymal monitors in patients with a GCS 5-6.
\end{abstract}

Keywords Pediatric trauma $\cdot$ Traumatic brain injury (TBI) $\cdot$ Intracranial pressure (ICP) monitor $\cdot$ Intracranial hypertension

\section{Introduction}

In 2013 alone, there were 640,000 emergency department (ED) visits and 18,000 hospital stays related to traumatic brain injury (TBI) in children [1]. This includes a spectrum of injury severity from concussion to coma/death, but mortality for severe TBI can be as high as $20 \%[2,3]$ and up to $40 \%$ in those children who present with a Glasgow Coma

Patrick T. Delaplain

pdelapla@uci.edu

1 Department of Surgery, University of California, Irvine Medical Center, 333 City Blvd West, Suite 1600, Orange, CA 92868, USA

2 Department of Pediatric Surgery, Children's Hospital Los Angeles, 4650 Sunset Blvd., Mailstop \#100, Los Angeles, CA 90027, USA

3 Department of Anesthesiology, University of Southern California, 1450 San Pablo Street Suite 360, Los Angeles, CA 90033, USA
Score (GCS) of 3 [4]. Early studies linking elevated intracranial pressure (ICP) with secondary injury and worse overall outcomes in children set the precedent for targeting intensive care unit (ICU) and surgical interventions towards reduction of intracranial hypertension [5].

In 2007, the Brain Trauma Foundation (BTF) Guidelines for TBI made specific recommendations regarding the placement of ICP monitors in adults with severe TBI (i.e., all patients with a GCS 3-8 and computed tomography [CT] evidence of TBI) [6]. Even with strong recommendations for invasive ICP monitoring in adults, adoption among pediatric trauma centers is highly variable and reported anywhere from 7 to $70 \%$ [2, 3, 7-16]. Despite a logical connection between ICP monitoring and improved outcomes, there is yet to be definitive evidence (adult or pediatric) which demonstrates improved survival with invasive monitoring techniques. The most recent wording of the adult BTF guidelines suggests only "management of severe TBI patients using information from ICP monitoring," and specific indications for the placement 
of ICP monitors are absent from the most recent adult and pediatric BTF guidelines [17, 18].

There is currently no consensus regarding the use of invasive ICP monitors in pediatric patients with TBI. We sought to provide a contemporary analysis of severe TBI in children and potentially identify a subset of patients that may benefit from invasive ICP monitoring. A study examining the National Trauma Data Bank (NTDB) using data from 2001-2006 demonstrated that while there was no overall difference in mortality for children with ICP monitors, patients with an initial GCS of 3 actually had a survival benefit with their placement [8]. However, this study evaluated the use of all the various ICP monitors, including intraparenchymal pressure monitors and ventricular drain monitors, and did not differentiate if there was a difference in mortality among the various ICP monitoring devices. We sought to determine the association between ICP monitors and invasive cerebral oxygen tension monitors and mortality in pediatric TBI patients, stratifying by device and GCS. We hypothesized that in more severely injured patients (GCS 3-4), there would be a decreased mortality associated with invasive monitoring devices.

\section{Methods}

\section{Data source and cohort}

This study was deemed exempt by the institutional review board, as it utilized a national deidentified database. The Pediatric Trauma Quality Improvement Program (TQIP) database, which collects a variety of patient and institutional variables for adults and children admitted to American College of Surgeons (ACS) trauma centers, was queried for trauma patents $\leq 16$ years old meeting historical BTF criteria for invasive ICP monitoring (presence of TBI and GCS $\leq 8$ ) between 2014 and 2016 . TBI was defined by international classifications of disease version-9 (ICD-9) event codes: 800-801.96, 803-804.99, and 850-854.19. Exclusion criteria included death within $48 \mathrm{~h}$ of admission and an abbreviated injury scale (AIS) $<3$ for the head. Information regarding the type of invasive monitoring was collected on all patients with AIS grade $\geq 1$ for the head. Pediatric TQIP follows National Trauma Data Standard Data Dictionary and collects the following field values for cerebral monitoring: (1) intraventricular drain/catheter (e.g., ventriculostomy, external ventricular drain); (2) intraparenchymal pressure monitor (e.g., Camino ${ }^{\circledR}$ bolt, subarachnoid bolt, intraparenchymal catheter); (3) intraparenchymal oxygen monitor (e.g., Licox ${ }^{\circledR}$ ).

\section{Patient demographics, characteristics, and outcomes}

The patient demographic and characteristic information collected included age, race, gender, mechanism of injury, injury severity score (ISS)/AIS, and comorbid conditions. Our primary outcome was mortality. Secondary outcomes evaluated included length of stay (LOS), intensive care unit (ICU) LOS, ventilator days, and complications. The complications included acute kidney injury (AKI), acute respiratory distress syndrome (ARDS), cardiac arrest, deep venous thrombosis (DVT), pneumonia, pulmonary embolism, urinary tract infection (UTI), and severe sepsis. We compared primary and secondary outcomes between patients who underwent ICP monitoring and those without ICP monitoring. All missing data points were not imputed but treated as missing data.

\section{Statistical analysis}

Categorical data were reported as percentages, and continuous data were reported as medians with interquartile range (IQR). Mann-Whitney $U$ test was used to compare continuous variables and Chi-square test was used to compare categorical variables for bivariate analysis. Odds of mortality was determined using a stepwise, hierarchical multivariable logistic regression model. All variables were eligible for inclusion in the multivariable model. These were first measured using a univariate logistic regression model and variables with a $p<0.2$ were included in a multivariable logistic regression model. We then performed a stepwise, hierarchical regression to select the model with the best fit for the outcome of interest-mortality. Since we included a binary outcome of mortality, we chose to use the Hosmer-Lemeshow test to evaluate our model. This test produces a Chi-square Hosmer-Lemeshow statistic and a $p$ value, which, if greater than 0.05 , suggests good fit. We did find that our models based on the Hosmer-Lemeshow test had good fit with a Hosmer-Lemeshow Chi-square statistic which was 2.94 , with a $p$ value $=0.44$. Additionally, the Nagelkerke $R$ square was 0.59 for the model. A secondary multivariable logistic regression analysis was performed to determine odds of mortality as stratified by type of invasive monitoring device (intraparenchymal pressure monitors vs. intraventricular monitors vs. oxygen tension monitors). This was then repeated with an additional stratification by a tripartite subdivision of GCS (3-4 vs. 5-6 vs. 7-8). The reference group for these analyses included patients with no invasive monitoring device. The risk of mortality was reported with odds ratio (OR) and $95 \%$ confidence interval (CI). Statistical significance was defined as $p<0.05$. All 
statistical analyses were performed with IBM SPSS Statistics for Windows, Version 24 (Armonk, NY: IBM Corp).

\section{Results}

\section{Baseline characteristics/unadjusted outcomes}

We identified 3,808 pediatric patients with TBI who met inclusion criteria. Of these patients, only $685(18.0 \%)$ had invasive ICP monitoring. There were 454 (66.3\%) with an intraparenchymal pressure monitor, $319(46.6 \%)$ with an intraventricular drain, and $31(4.5 \%)$ with an intraparenchymal oxygen monitor. There was some overlap between these categories as $30.7 \%$ of patients with an intraventricular drain also had an intraparenchymal pressure monitor, and $21.6 \%$ of patients with an intraparenchymal pressure monitor had an intraventricular drain. On the other hand, $<5 \%$ of either intraventricular drains or intraparenchymal pressure monitors had an oxygen monitor. Finally, most patients with an intraparenchymal oxygen monitor had some other form of monitoring device: $32.3 \%$ had an intraventricular drain and $67.7 \%$ of patients had a pressure monitor.

Overall, most patients were male (62.7\%) with a median age of 5 years (IQR 11), though infants $<1$ year of age made up the largest portion of the study population (23.4\%). The most common mechanisms of injury were fall $(33.2 \%)$ and motor vehicle collision $(26.3 \%)$.

Patients who underwent ICP monitoring were older (8 vs. 4 years, $p<0.001)$ and had a higher median ISS (26 vs. $16, p<0.001$ ) than those that did not have invasive monitoring. These patients were also more likely to have severe concurrent thoracoabdominal injuries as indicated by a higher percentage of AIS grade of $>3$ (Table 1 ). While pedestrian injuries, gunshot wounds, and motor vehicle collisions were all more common in patients with invasive ICP monitoring, there was a significantly higher incidence of falls in those without $(37.8 \%$ vs. $12.1 \%$, $p<0.001$, Table 1 ).

The unadjusted outcomes were worse in nearly all examined categories for those patients with ICP monitoring including longer LOS (19 vs. 4 days, $p<0.001$ ), longer ICU LOS (13 vs. 2 days, $p<0.001$ ), and more ventilator days (9 vs. $1, p<0.001$ ). Similarly, all examined complications, except for pulmonary embolism $(p=0.095)$, were increased in the ICP monitoring group; all $p<0.001$ (Table 2). The unadjusted incidence of mortality was three times higher in patients with invasive ICP monitoring compared to those without ICP monitoring ( $15.9 \%$ vs. $5.3 \%, p<0.001)$.
Table 1 Demographics of pediatric trauma patients with and without ICP monitors

\begin{tabular}{llll}
\hline Characteristics & $\begin{array}{l}\text { ICP monitor }- \\
(n=3123)\end{array}$ & $\begin{array}{l}\text { ICP monitor }+ \\
(n=685)\end{array}$ & $p$ value \\
\hline Age, year, median (IQR) & $4.0(11)$ & $8.0(10)$ & $<0.001$ \\
Male, $n(\%)$ & $1929(61.8 \%)$ & $459(67.0 \%)$ & 0.010 \\
Race, $n(\%)$ & $1848(59.2 \%)$ & $385(56.2 \%)$ & 0.153 \\
White & $499(21.3 \%)$ & $161(29.5 \%)$ & $<0.001$ \\
Black & $591(18.9 \%)$ & $117(17.1 \%)$ & 0.261 \\
Hispanic & $92(4.7 \%)$ & $16(4.0 \%)$ & 0.513 \\
Asian & $16.0(15)$ & $26.0(13)$ & $<0.001$ \\
ISS, median (IQR) & & & \\
Comorbidities, $n(\%)$ & $6(0.2 \%)$ & $2(0.1 \%)$ & 0.605 \\
Diabetes & $77(2.5 \%)$ & $9(1.3 \%)$ & 0.066 \\
COPD & & & \\
AIS (grade $>3), n(\%)$ & $184(5.9 \%)$ & $92(13.4 \%)$ & $<0.001$ \\
Thorax & $71(2.3 \%)$ & $34(5.0 \%)$ & $<0.001$ \\
Abdomen & & & \\
Mechanism of injury, $n(\%)$ & $135(4.3 \%)$ & $31(4.5 \%)$ & 0.814 \\
Bicyclist & $204(6.5 \%)$ & $92(13.4 \%)$ & $<0.001$ \\
Pedestrian & $7(0.2 \%)$ & $3(0.4 \%)$ & 0.322 \\
Stab & $49(1.6 \%)$ & $37(5.4 \%)$ & $<0.001$ \\
GSW & $1181(37.8 \%)$ & $83(12.1 \%)$ & $<0.001$ \\
Fall & $741(23.7 \%)$ & $259(37.8 \%)$ & $<0.001$ \\
MVC & $21(0.7 \%)$ & $10(1.5 \%)$ & 0.038 \\
Suicide attempt & & & \\
\hline
\end{tabular}

$I C P$ intracranial pressure, $I S S$ injury severity score, $I Q R$ interquartile range, $C O P D$ chronic obstructive pulmonary disease, $A I S$ abbreviated injury scale, $G S W$ gunshot wound, $M V C$ motor vehicle collision

\section{Multivariable logistic regression for odds of mortality}

After initial comparison, a selection of bivariate variables were included in a multivariable logistic regression model: presence of an ICP monitor, ISS $\geq 25$, spine injury, pneumonia, severe sepsis, and AKI. Severe AIS-Head and GCS motor $\leq 3$ were also included in the model because of their independent association with mortality in TBI [19]. While ISS $\geq 25$ (OR 10.4, CI 7.15-15.12, $p<0.001$ ) and AKI (OR 6.93 , CI 1.68-28.56, $p=0.007$ ) had the highest association with mortality in our model, the presence of an ICP monitor was an independent risk factor for mortality (OR 1.82, CI $1.36-2.44, p<0.001$, Table 3).

We then performed a secondary analysis by including type of invasive ICP monitor and dividing GCS into three categories (GCS 3-4 vs. 5-6 vs. 7-8) with the initial multivariable logistic regression model. Both intraventricular drain (OR 1.89, CI 1.3-2.7, $p=0.001$, Table 4) and intraparenchymal pressure monitor (OR 1.86, CI 1.32-2.6, $p<0.001$, Table 4) were independently associated with an increased likelihood of mortality regardless of GCS, while 
Table 2 Clinical outcomes in pediatric trauma patients with and without ICP monitors

\begin{tabular}{lllr}
\hline Outcome & $\begin{array}{l}\text { ICP monitor }- \\
(n=3123)\end{array}$ & ICP monitor $+(n=685)$ & $p$ value \\
\hline LOS, days, median (IQR) & $4.0(7)$ & $19.0(18)$ & $<0.001$ \\
ICU, days, median (IQR) & $2.0(6)$ & $13.0(11)$ & $<0.001$ \\
Ventilator, days, median (IQR) & $1.0(4)$ & $9.0(9)$ & $<0.001$ \\
Complications, $n(\%)$ & & $7(1.0 \%)$ & $<0.001$ \\
AKI & $2(0.1 \%)$ & $19(2.8 \%)$ & $<0.001$ \\
ARDS & $17(0.5 \%)$ & $24(3.5 \%)$ & $<0.001$ \\
Cardiac arrest with CPR & $42(1.3 \%)$ & $33(4.8 \%)$ & $<0.001$ \\
DVT & $29(0.9 \%)$ & $99(14.5 \%)$ & $<0.001$ \\
Pneumonia & $71(2.3 \%)$ & $2(0.3 \%)$ & 0.095 \\
Pulmonary embolism & $2(0.1 \%)$ & $31(4.5 \%)$ & $<0.001$ \\
UTI & $22(0.7 \%)$ & $10(1.5 \%)$ & $<0.001$ \\
Severe sepsis & $5(0.2 \%)$ & $250(36.5 \%)$ & $<0.001$ \\
Craniotomy/craniectomy & $298(9.5 \%)$ & $109(15.9 \%)$ & $<0.001$ \\
Mortality, $n$ (\%) & $164(5.3 \%)$ & & \\
\hline
\end{tabular}

$L O S$ length of stay, ICU intensive care unit, $A R D S$ acute respiratory distress syndrome, $C P R$ cardiopulmonary resuscitation, $D V T$ deep vein thrombosis, $U T I$ urinary tract infection
Table 3 Multivariable logistic regression analysis for risk of mortality in pediatric traumatic brain injury patients

\begin{tabular}{lclc}
\hline Risk factor & OR & CI & $p$ value \\
\hline ICP monitor & 1.82 & $1.36-2.44$ & $<0.001$ \\
ISS $\geq 25$ & 10.4 & $7.15-15.12$ & $<0.001$ \\
AIS-Head $\geq 4$ & 2.05 & $1.19-3.54$ & 0.01 \\
GCS-Motor $\leq 3$ & 3.47 & $2.05-5.89$ & $<0.001$ \\
Spine injury & 1.23 & $0.87-1.74$ & 0.243 \\
Pneumonia & 0.5 & $0.28-0.9$ & 0.021 \\
Severe sepsis & 0.51 & $0.1-2.49$ & 0.4 \\
Acute kidney injury & 6.93 & $1.68-28.56$ & 0.007 \\
Mechanism: MVC & 0.86 & $0.64-1.17$ & 0.337 \\
Mechanism: GSW & 1.69 & $0.96-2.98$ & 0.07 \\
Craniotomy & 0.61 & $0.44-0.86$ & 0.005 \\
\hline
\end{tabular}

ICP intracranial pressure, ISS Injury Severity Score, AIS Abbreviated Injury Scale, GCS Glasgow Coma Scale, $M V C$ Motor Vehicle Collision, $G S W$ gunshot wound

intraparenchymal oxygen monitoring was not (OR 0.47 , CI $0.11-2.05, p=0.31$, Table 4 ). When stratifying the subgroups of ICP monitor device type by GCS score, patients with GCS 5-6 were associated with a statistically significant increase in odds of mortality (Table 4).

\section{Discussion}

We reported that the utilization of invasive intracranial monitoring among pediatric patients with severe TBI was around $18 \%$. Patients who underwent invasive monitoring were older, had more severe injuries, and were more likely
Table 4 Adjusted analysis for mortality in pediatric patients with severe traumatic brain injury

\begin{tabular}{lccr}
\hline Risk factor & OR & CI & $p$ value \\
\hline Any invasive monitor & 1.82 & $1.36-2.44$ & $<0.001$ \\
GCS 3-4 & 1.35 & $0.98-1.87$ & 0.064 \\
GCS 5-6 & 5.02 & $1.75-14.39$ & 0.003 \\
GCS 7-8 & 0.85 & $0.16-4.49$ & 0.849 \\
Intraventricular drain/monitor & 1.89 & $1.3-2.7$ & 0.001 \\
GCS 3-4 & 1.41 & $0.93-2.15$ & 0.106 \\
GCS 5-6 & 6.77 & $1.97-23.2$ & 0.002 \\
GCS 7-8 & 1.24 & $0.14-11.46$ & 0.439 \\
Intraparenchymal pressure monitor & 1.86 & $1.32-2.6$ & $<0.001$ \\
GCS 3-4 & 1.44 & $0.99-2.1$ & 0.055 \\
GCS 5-6 & 4.09 & $1.29-13$ & 0.017 \\
GCS 7-8 & 1.08 & $0.2-5.72$ & 0.93 \\
Intraparenchymal oxygen monitor & \\
& 0.47 & $0.11-2.05$ & 0.316 \\
\hline
\end{tabular}

Controlled for ISS $\geq 25$, AIS-Head (grade 4 or 5 ), GCS-Motor $\leq 3$, spine injury, pneumonia, severe sepsis, acute kidney injury, mechanism (gunshot wound or motor vehicle collision), and craniotomy

GCS Glasgow Coma Scale

${ }^{\text {a }}$ Model contains too few complete cases to stratify by GCS

to have a non-fall mechanism of injury. Invasive monitoring patients also had a higher incidence of both in-hospital mortality and in-hospital complications (AKI, ARDS, cardiac arrest, DVT, pneumonia, UTI, severe sepsis). The use of an ICP monitor was an independent risk factor for mortality. Specifically, intraparenchymal pressure monitors and intraventricular drains/monitors were independently associated with an increased risk of mortality, while intraparenchymal 
oxygen monitors showed no difference. Contrary to our hypothesis, despite adjusting for invasive monitor type and presenting GCS, there did not appear to be any specific group that saw a mortality benefit and the risk of mortality was increased for several groups.

There is considerable variability in the reported use of invasive ICP monitoring in the literature regarding pediatric patients depending on the database used, patient's age and definition of severe TBI [2, 3, 7-16], and the utilization rate $(18 \%)$ in our study was within that range. This wide variation could be secondary to highly varied utilization between individual institutions. Bennett et al., for instance, had very similar inclusion criteria to our study and showed an overall utilization rate of around $32.5 \%$ using a linked Pediatric Health Information (PHIS)-National Trauma Databank (NTDB) database, though individual institution utilization rates varied anywhere between 5 and $50 \%$ within their study [2]. Similarly, Van Cleve et al. had an overall utilization rate of $27 \%$ but found that adult trauma centers were more likely to place invasive monitoring devices into pediatric patients than combined pediatric/adult trauma centers [7]. Roumeliotis et al. actually speculated that the low rates of ICP monitor usage might be due to more rapid improvement or deterioration of clinical status than adult patients [10].

Though the increased odds of mortality seen with ICP monitoring (OR 1.82) in our study was modest compared to other variables such as ISS $\geq 25$ (OR 10.4) or GCSMotor $\leq 3$ (OR 3.47), it was still present after adjusting for potential confounders. The mortality risk associated with invasive ICP monitoring has not been demonstrated in other pediatric studies that evaluated for this association $[2,8,9$, $12,13,15,16]$. The published unadjusted mortality rates for pediatric patients with severe TBI who undergo ICP monitoring are frequently higher, but many studies showed no difference in mortality after adjusting for other covariables $[2,15,16]$. Bennett et al. had very similar raw mortality rates to our study (ICP [18.5\%] vs. no ICP [9.5\%]), but after using propensity scoring to adjust for a variety of variables, there was no significant difference in likelihood of mortality [2]. Some of this difference might be explained by the inclusion of hospital clustering in their model, which we were unable to do. It is also possible that the limited number of centers included in their study (31 pediatric hospitals) is less generalizable to lower volume pediatric centers, and the ICP monitors have worse outcomes outside of those highvolume centers.

Several other authors showed a reduction in survival with the use of invasive monitoring devices in pediatric patients with severe TBI $[8,12,13]$. Alali et al., for example, demonstrated a 50\% reduction in mortality with the use of invasive ICP monitors [13]. However, they excluded patients with significant injuries to other body regions, which could explain this difference as we did not look exclusively at isolated head injuries. And, though Arunkumar et al. also showed a reduction in mortality with invasive ICP monitoring, their study had only 50 cases [12].

Unfortunately, this conflicting data from pediatric studies cannot be clarified by application of adult research. While there are multiple adult studies showing a modest reduction in mortality with placement of invasive ICP monitors [20-26], there are a number that demonstrate either no difference [27, 28] or worse survival [29-31]. In fact, the only randomized controlled trial on the topic failed to show any difference between those treated with invasive ICP monitoring with strict ICP control $(<20 \mathrm{mmHg})$, and those managed with imaging findings and physical exam [28].

Alkhoury et al. used the NTDB to look at the outcomes of severe pediatric TBI patients with invasive ICP monitoring. After adjustment for other variables, ICP monitoring was associated with a significant reduction in mortality (OR 0.64 ) but only for those children with a GCS of 3 [8]. This led us to hypothesize that there may be a subset of patients in the TQIP database who similarly benefited from ICP monitoring. However, our findings did not support our hypothesis. Unfortunately, stratifying patients by GCS had the opposite effect. While both intraventricular and intraparenchymal pressure monitors were associated with a modest increase in mortality (OR 1.89 and 1.86, respectively), this was specifically seen in the subgroup of patients with a GCS of 5-6. For patients with a GCS of 5-6, there was nearly a fivefold increased risk of mortality with any invasive type of monitor device; this risk was highest in children with intraventricular drain (OR 6.77). This could potentially be explained by how the ICP monitor is interpreted and utilized by providers. If patients with a lower GCS have poor outcomes regardless of intervention and patients with a GCS of 7-8 are more likely to improve, the use of an ICP monitor would be less likely to change the outcome compared with a more middling severe TBI group. However, without knowing the interventions that were undertaken in response to intracranial hypertension, this remains speculative.

It is unclear why invasive monitoring has failed to improve outcomes in pediatric trauma patients. In 2013, a study looking at high-dose barbiturates for refractory intracranial hypertension in pediatric patients showed better long-term outcomes when ICPs were controlled compared to uncontrolled ICPs [32], but this finding does not seem to translate to monitoring having a benefit. Balakrishnan et al. hypothesized that it was related to timing, but their single institution study failed to show any difference in mortality, LOS or functional outcomes between early $(<6 \mathrm{~h})$ and late placement (6-72 h) of ICP monitors in pediatric patients [16]. It is possible that it is our interpretation of ICPs and cerebral perfusion pressures that limit the utility of monitors, as some exploratory studies have shown algorithmic and continuous approaches to ICP monitors may have prognostic 
value above intermittent measurements [33-35]. Newer technologies (e.g., cerebral oxygen tension) have also shown some promise over more traditional methods of invasive ICP monitoring [7]. While intraparenchymal oxygen monitors did not have a statistically significant association with mortality in this study, they only made up $4.5 \%$ of the patient population. It is possible that more patients may prove this modality to be beneficial.

Our study represents the largest study using the unique variables of the pediatric TQIP database. This allowed us to stratify risk by invasive monitor type, which has not been previously done in the pediatric literature and has been conflicting in adult literature $[26,27]$. We also simultaneously stratified for GCS and other variables to determine the association between invasive monitoring devices and mortality, representing the most extensive adjustment for covariables in pediatric patients to date.

This study also has several important limitations-many inherent to retrospective database studies. Though we attempted to adjust for selection bias, it is still present as with all retrospective studies. In addition, the TQIP database only includes those children that are admitted and does not account for non-TQIP centers. Especially in light of other studies showing the significant variability between individual pediatric centers, TQIP centers may not be representative of all pediatric hospitals. The database also lacks pertinent information (e.g., socioeconomic status, presence of coagulopathy), which may be prognostic in TBI outcomes. In addition, missing pertinent variables that are not included in TQIP include center volume, institutional protocols for the placement of ICP monitor and management of intracranial hypertension, actual ICP/CPP measurements, timing of invasive monitor placement, and other potentially prognostic variables (e.g., pupillary response). Without knowing what interventions were taken for intracranial hypertension, it is difficult to determine whether this association with mortality is related to the device or how providers utilize the information gained from them. There is also some degree of overlap between monitor types, particularly for intraparenchymal oxygen monitors, which may skew the effect that an individual monitor has on mortality. Furthermore, we cannot track long-term neurologic outcomes for those patients that survive, which is a significant limitation of this database, because TQIP only provides index hospitalization data. While we adjusted for injury severity using GCS-Motor scores and AIS-Head scores, lack of specific imaging data is a significant limitation of the TQIP database, and it is possible that patients in one group had more severe injuries by imaging criteria.

In conclusion, our study contributes to the growing body of literature that invasive ICP monitors are infrequently utilized in pediatric patients, have unclear benefit, and may actually be associated with increased mortality in certain pediatric populations. While newer technologies, such as cerebral oxygen tension or continuous cerebral perfusion pressures, may prove to be beneficial over time, there is insufficient evidence to support widespread use in pediatric patients with severe TBI based on our findings. A prospective, randomized trial is desperately needed to determine which patients, if any, are likely to benefit from these monitoring devices.

Funding The project was funded in its entirety by the Department of Surgery at the University of California, Irvine Medical Center.

\section{Compliance with ethical standards}

Conflict of interest None of the authors of this manuscript has any significant financial conflicts of interest to disclose.

Ethical approval This study was determined to be IRB exempt by the IRB Board at the University of California, Irvine. All procedures performed in studies involving human participants were in accordance with the ethical standards of the institutional and/or national research committee and with the 1964 Helsinki declaration and its later amendments or comparable ethical standards.

\section{References}

1. Taylor CA, Bell JM, Breiding MJ, Xu L (2017) Traumatic brain injury-related emergency department visits, hospitalizations, and deaths-United States, 2007 and 2013. MMWR Surveill Summ 66(9):1-16. https://doi.org/10.15585/mmwr.ss6609a1

2. Bennett TD, DeWitt PE, Greene TH, Srivastava R, Riva-Cambrin J, Nance ML, Bratton SL, Runyan DK, Dean JM, Keenan HT (2017) Functional outcome after intracranial pressure monitoring for children with severe traumatic brain injury. JAMA pediatrics 171(10):965-971. https://doi.org/10.1001/jamapediat rics. 2017.2127

3. Sigurta A, Zanaboni C, Canavesi K, Citerio G, Beretta L, Stocchetti N (2013) Intensive care for pediatric traumatic brain injury. Intensive Care Med 39(1):129-136. https://doi.org/10.1007/s0013 4-012-2748-0

4. Murphy S, Thomas NJ, Gertz SJ, Beca J, Luther JF, Bell MJ, Wisniewski SR, Hartman AL, Tasker RC (2017) Tripartite stratification of the glasgow coma scale in children with severe traumatic brain injury and mortality: an analysis from a multicenter comparative effectiveness study. J Neurotrauma. https:// doi.org/10.1089/neu.2016.4793

5. Pfenninger J, Kaiser G, Lutschg J, Sutter M (1983) Treatment and outcome of the severely head injured child. Intensive Care Med 9(1):13-16

6. Brain Trauma F, American Association of Neurological S, Congress of Neurological S (2007) Guidelines for the management of severe traumatic brain injury. J Neurotrauma 24(Suppl 1):S1-106. https://doi.org/10.1089/neu.2007.9999

7. Van Cleve W, Kernic MA, Ellenbogen RG, Wang J, Zatzick DF, Bell MJ, Wainwright MS, Groner JI, Mink RB, Giza CC, Boyle LN, Mitchell PH, Rivara FP, Vavilala MS (2013) National variability in intracranial pressure monitoring and craniotomy for children with moderate to severe traumatic brain injury. Neurosurgery 
73(5):746-752. https://doi.org/10.1227/neu.000000000000009 7 (discussion 752; quiz 752)

8. Alkhoury F, Kyriakides TC (2014) Intracranial pressure monitoring in children with severe traumatic brain injury: national trauma data bank-based review of outcomes. JAMA Surg 149(6):544548. https://doi.org/10.1001/jamasurg.2013.4329

9. Bennett TD, Riva-Cambrin J, Keenan HT, Korgenski EK, Bratton SL (2012) Variation in intracranial pressure monitoring and outcomes in pediatric traumatic brain injury. Arch Pediatr Adolesc Med 166(7):641-647. https://doi.org/10.1001/archpediat rics.2012.322

10. Roumeliotis N, Pettersen G, Crevier L, Emeriaud G (2015) ICP monitoring in children: why are we not adhering to guidelines? Child's Nervous Syst 31(11):2011-2014. https://doi.org/10.1007/ s00381-015-2837-9

11. Dixon RR, Nocera M, Zolotor AJ, Keenan HT (2016) Intracranial pressure monitoring in infants and young children with traumatic brain injury. Pediatric Crit Care Med 17(11):1064-1072. https:// doi.org/10.1097/pcc.0000000000000937

12. Arunkumar S, Devi BI, Shukla D, Reddy M (2016) Is intracranial pressure monitoring useful in children with severe traumatic brain injury? Neurol India 64(5):958-961. https://doi. org/10.4103/0028-3886.190259

13. Alali AS, Gomez D, Sathya C, Burd RS, Mainprize TG, Moulton R, Falcone RA Jr, de Mestral C, Nathens A (2015) Intracranial pressure monitoring among children with severe traumatic brain injury. J Neurosurg Pediatrics 16(5):523-532. https://doi. org/10.3171/2015.3.PEDS14507

14. Morris KP, Forsyth RJ, Parslow RC, Tasker RC, Hawley CA, Group UKPTBIS, Paediatric Intensive Care Society Study G (2006) Intracranial pressure complicating severe traumatic brain injury in children: monitoring and management. Intensive Care Med 32(10):1606-1612. https://doi.org/10.1007/s0013 4-006-0285-4

15. Salim A, Hannon M, Brown C, Hadjizacharia P, Backhus L, Teixeira PG, Chan LS, Ford H (2008) Intracranial pressure monitoring in severe isolated pediatric blunt head trauma. Am Surg 74(11):1088-1093

16. Balakrishnan B, Zhang L, Simpson PM, Hanson SJ (2018) Impact of the timing of placement of an intracranial pressure monitor on outcomes in children with severe traumatic brain injury. Pediatr Neurosurg 53(6):379-386. https://doi.org/10.1159/000494028

17. Carney N, Totten AM, O'Reilly C, Ullman JS, Hawryluk GW, Bell MJ, Bratton SL, Chesnut R, Harris OA, Kissoon N, Rubiano AM, Shutter L, Tasker RC, Vavilala MS, Wilberger J, Wright DW, Ghajar J (2017) Guidelines for the management of severe traumatic brain injury. Neurosurgery 80(1):6-15. https://doi. org/10.1227/NEU.0000000000001432

18. Kochanek PM, Carney N, Adelson PD, Ashwal S, Bell MJ, Bratton S, Carson S, Chesnut RM, Ghajar J, Goldstein B, Grant GA, Kissoon N, Peterson K, Selden NR, Tasker RC, Tong KA, Vavilala MS, Wainwright MS, Warden CR (2012) Guidelines for the acute medical management of severe traumatic brain injury in infants, children, and adolescents-second edition Pediatric Crit Care Med J Soc Crit Care Med World Federation Pediatric Intensive Crit Care Soc 13(Suppl 1):82. DOI: 10.1097/ PCC.0b013e31823f435c.

19. Timmons SD, Bee T, Webb S, Diaz-Arrastia RR, Hesdorffer D (2011) Using the abbreviated injury severity and Glasgow Coma Scale scores to predict 2 -week mortality after traumatic brain injury. J Trauma 71(5):1172-1178. https://doi.org/10.1097/ TA.0b013e 31822b0f4b

20. Agrawal D, Raghavendran K, Schaubel DE, Mishra MC, Rajajee $\mathrm{V}$ (2016) A propensity score analysis of the impact of invasive intracranial pressure monitoring on outcomes after severe traumatic brain injury. J Neurotrauma 33(9):853-858. https://doi. org/10.1089/neu.2015.4015

21. Dawes AJ, Sacks GD, Cryer HG, Gruen JP, Preston C, Gorospe D, Cohen M, McArthur DL, Russell MM, Maggard-Gibbons M, Ko CY (2015) Intracranial pressure monitoring and inpatient mortality in severe traumatic brain injury: a propensity score-matched analysis. J Trauma Acute Care Surg 78(3):492-501. https://doi. org/10.1097/TA.0000000000000559(discussion 501-492)

22. Farahvar A, Gerber LM, Chiu YL, Carney N, Hartl R, Ghajar J (2012) Increased mortality in patients with severe traumatic brain injury treated without intracranial pressure monitoring. J Neurosurg 117(4):729-734. https://doi.org/10.3171/2012.7.JNS111816

23. MacLaughlin BW, Plurad DS, Sheppard W, Bricker S, Bongard F, Neville A, Smith JA, Putnam B, Kim DY (2015) The impact of intracranial pressure monitoring on mortality after severe traumatic brain injury. Am J Surg 210(6):1082-1086. https://doi. org/10.1016/j.amjsurg.2015.08.007

24. Talving P, Karamanos E, Teixeira PG, Skiada D, Lam L, Belzberg H, Inaba K, Demetriades D (2013) Intracranial pressure monitoring in severe head injury: compliance with Brain Trauma Foundation guidelines and effect on outcomes: a prospective study. J Neurosurg 119(5):1248-1254. https://doi.org/10.3171/2013.7.JNS12 2255

25. You W, Feng J, Tang Q, Cao J, Wang L, Lei J, Mao Q, Gao G, Jiang J (2016) Intraventricular intracranial pressure monitoring improves the outcome of older adults with severe traumatic brain injury: an observational, prospective study. BMC Anesthesiol 16(1):35. https://doi.org/10.1186/s12871-016-0199-9

26. Liu H, Wang W, Cheng F, Yuan Q, Yang J, Hu J, Ren G (2015) External ventricular drains versus intraparenchymal intracranial pressure monitors in traumatic brain injury: a prospective observational study. World Neurosurg 83(5):794-800. https://doi. org/10.1016/j.wneu.2014.12.040

27. Aiolfi A, Khor D, Cho J, Benjamin E, Inaba K, Demetriades D (2018) Intracranial pressure monitoring in severe blunt head trauma: does the type of monitoring device matter? J Neurosurg 128(3):828-833. https://doi.org/10.3171/2016.11.JNS162198

28. Chesnut RM, Temkin N, Carney N, Dikmen S, Rondina C, Videtta W, Petroni G, Lujan S, Pridgeon J, Barber J, Machamer J, Chaddock K, Celix JM, Cherner M, Hendrix T, Global Neurotrauma Research G (2012) A trial of intracranial-pressure monitoring in traumatic brain injury. N Engl J Med 367262471 2481. 10.1056/ NEJMoa1207363

29. Piccinini A, Lewis M, Benjamin E, Aiolfi A, Inaba K, Demetriades D (2017) Intracranial pressure monitoring in severe traumatic brain injuries: a closer look at level 1 trauma centers in the United States. Injury 48(9):1944-1950. https://doi.org/10.1016/j.injur y.2017.04.033

30. Shafi S, Diaz-Arrastia R, Madden C, Gentilello L (2008) Intracranial pressure monitoring in brain-injured patients is associated with worsening of survival. J Trauma 64(2):335-340. https://doi. org/10.1097/TA.0b013e31815dd017

31. Tang A, Pandit V, Fennell V, Jones T, Joseph B, O'Keeffe T, Friese RS, Rhee P (2015) Intracranial pressure monitor in patients with traumatic brain injury. J Surg Res 194(2):565-570. https:// doi.org/10.1016/j.jss.2014.11.017

32. Mellion SA, Bennett KS, Ellsworth GL, Moore K, Riva-Cambrin J, Metzger RR, Bratton SL (2013) High-dose barbiturates for refractory intracranial hypertension in children with severe traumatic brain injury. Pediatric Crit Care Med J Soc Crit Care Med World Federation of Pediatric Intensive Crit Care Soc 14(3):239 247. https://doi.org/10.1097/PCC.0b013e318271c3b2

33. Guiza F, Meyfroidt G, Lo TY, Jones PA, Van den Berghe G, Depreitere B (2016) Continuous optimal CPP based on minuteby-minute monitoring data: a study of a pediatric population. Acta 
Neurochirurgica Suppl 122:187-191. https://doi.org/10.1007/9783-319-22533-3 38

34. Lo T, Piper I, Depreitere B, Meyfroidt G, Poca M, Sahuquillo J, Durduran T, Enblad P, Nilsson P, Ragauskas A, Kiening K, Morris K, Agbeko R, Levin R, Weitz J, Park C, Davis P (2018) KidsBrainIT: a new multi-centre, multi-disciplinary, multi-national paediatric brain monitoring collaboration. Acta Neurochirurgica Suppl 126:39-45. https://doi.org/10.1007/978-3-319-65798-1_9

35. Young AM, Donnelly J, Czosnyka M, Jalloh I, Liu X, Aries MJ, Fernandes HM, Garnett MR, Smielewski P, Hutchinson PJ, Agrawal S (2016) Continuous multimodality monitoring in children after traumatic brain injury-preliminary experience. PLoS ONE 11(3):e0148817. https://doi.org/10.1371/journal.pone.01488 17
36. Figaji AA, Zwane E, Thompson C, Fieggen AG, Argent AC, Le Roux PD, Peter JC (2009) Brain tissue oxygen tension monitoring in pediatric severe traumatic brain injury. Part 1: Relationship with outcome. Child's Nervous Syst 25(10):1325-1333. https:// doi.org/10.1007/s00381-009-0822-x

Publisher's Note Springer Nature remains neutral with regard to jurisdictional claims in published maps and institutional affiliations. 